\title{
Multifunctional Testing Rig for Machinery Safety Equipment
}

\author{
Stefan Vöth ${ }^{1, *}$ Julian Tschersich ${ }^{1}$, Tim Schwartz ${ }^{1}$ \\ ${ }^{1}$ Technische Hochschule Georg Agricola, Centre for Drive and Lifting Technology ZAFT, Bochum, \\ Germany
}

\begin{abstract}
At the Centre of Drive and Lifting Technology ZAFT of Technische Hochschule Georg Agricola a new testing device will be available. The device is suitable for testing drivetrain components like safety clutches and hoist safety components like snag protection devices. In focus are continuous tests with regard to fatigue as well as transient tests with regard to switching characteristics. The article gives information on requirements on the testing rig out of the main purpose and out of the given environment. Furthermore concept, main data and engineering design of this equipment are demonstrated. Aspects and first results of the mechanical assembly are shown.
\end{abstract}

\section{Projects at ZAFT}

At the Centre for Drive and Lifting Technology ZAFT different projects related to drive and lifting technology are followed up. Examples are following:

Ship-to-shore cranes are vital elements of container port operations. They are used to load and to unload containers. One case of emergency happening in this context is a container getting stuck within the ship construction during lifting operation with higher speed (so called snag case). To limit the loads occurring to the hoist and the structure of the crane in this situation special safety devices are used (Snag protection devices). The development of concepts for those systems is part of activities at ZAFT [1].

Mining machinery like crushers is exposed to high variable loads. Temporarily the loads can exceed the loads permissible for the equipment. To prevent damage to the machinery safety couplings are implemented to the drivetrain. Those couplings have to meet certain properties to show the system behaviour required. Of interest are for example reaction times and stability of switching torques. The development of those safety couplings is part of activities at ZAFT [2].

\section{Objectives}

The testing rig is planned to serve different purposes.

First purpose is the testing of components in drive trains. It is intended to execute continuous and transient tests especially on safety clutches. Continuous tests are suitable for

\footnotetext{
${ }^{*}$ Corresponding author: stefan.voeth@thga.de
} 
example to check durability of the components. Transient tests are carried out to reveal the dynamic behaviour of them. The testing rig is rated for $\mathrm{P}=45 \mathrm{~kW} \mathrm{n}=291.4 \mathrm{~min}^{-1}$.

Second purpose is the testing of safety devices for hoists. For this, a hoist is system planned. The winch is to be constituted by using above-mentioned drivetrain with a rope drum unit instead of a specimen. The pulley is located in a pulley tower of maximum achievable height. Intention is a hoisting process with following maximum data:

- Acceleration

$$
\begin{array}{ll}
\text { - Acceleration } & \mathrm{a}=1.0 \mathrm{~m} / \mathrm{s}^{2} \\
\text { - Acceleration time } & \mathrm{t}_{\mathrm{a}}=0.5 \mathrm{~s} \\
\text { - Maximum speed } & \mathrm{v}_{\max }=0.5 \mathrm{~m} / \mathrm{s} \\
\text { - Maximum hoisting height } & \mathrm{h}_{\max }=3.0 \mathrm{~m} \\
\text { - Total process time } & \mathrm{t}_{\mathrm{tot}}=6.5 \mathrm{~s} .
\end{array}
$$$$
\text { - Maximum hoisting height } \mathrm{h}_{\max }=3.0 \mathrm{~m}
$$

\section{Boundary conditions}

\subsection{Floor load}

The testing rig will have a considerable mass. This will be of use due to the dynamic forces expected. The mass is acting as a filter and reducing dynamic loads to the ground. Looking on this the restricted floor pressure of $p=12 \mathrm{kN} / \mathrm{m}^{2}$ had to be regarded. This sets the maximum weight of a test bed of $A=1.5 \mathrm{mx} 5.0 \mathrm{~m}$ to $\mathrm{m}=9175 \mathrm{~kg}$, including all installations on the test bed. Similar considerations apply for the pulley tower. All plans had to be carried out with regard to this. The situation planned was discussed with and proofed by a static expert.

\subsection{Safety regulations}

According to BGDV6 of Deutsche Gesetzliche Unfallversicherung (DGUV) a safety clearance from rigid edges of surroundings to rigid edges of cranes of $\mathrm{s}=0.5 \mathrm{~m}$ has to be kept [3]. This applies to the roof, to the walls and to any object below the crane if people presence is given in these zones. In the present case, the planned tower should be of maximum height. With a lowest rigid edge of the crab at $1=4.73 \mathrm{~m}$ (Fig. 1) above floor the maximum height of the tower must not exceed $\mathrm{h}_{\max }=4.23 \mathrm{~m}$.

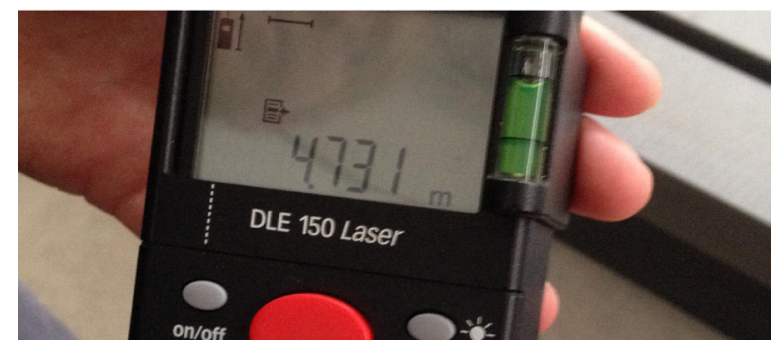

Fig. 1. Height of lowest rigid crab edge

\subsection{Safety concept}

The testing rig is an equipment planned and built for research purposes. Configurations are set up for different modes of operation: finishing operation, continuous operation, switching operation and hoisting operation. Each operation, that means research purpose, is planned for a period of up to a maximum of three years. Due to this the testing device is exempted 
from the machine directive. A declaration of conformity is not established. Risk analysis and operations instructions are created anyway [4]. A multi-stage concept is provided for obtaining safety.

\section{Design}

\subsection{Mechanical}

The mechanical design consists of a drive side, the specimen slot and the load side, all located on the test bed.

An asynchronous motor drives the testing rig via a frequency inverter with energy recovery. Behind the motor a disc brake is located. This brake consists of two identical brakes acting on one disc. By this a stepped braking torque may be realized. Behind the brake a gear for the transformation of the mechanical performance on a level of lower speed is located. Between motor and brake are two clutches located. A safety clutch for the protection of the drivetrain and an aligning coupling (Fig. 2).

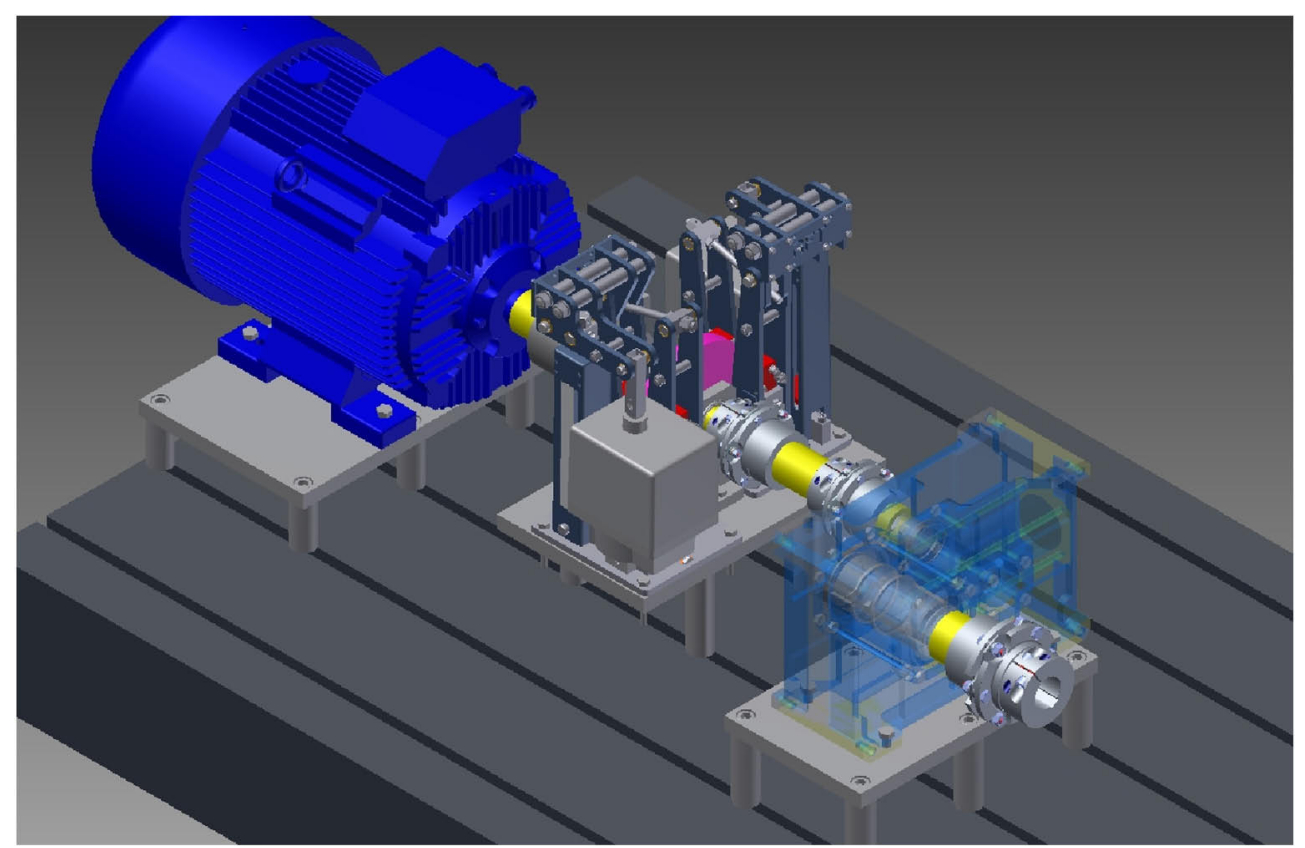

Fig. 2. Mechanical design of the drive side of testing rig

On the load side the performance is transformed back on a level of higher speed again in the first step. On this high-speed level are located two brakes. At first a magnet powder brake and behind a brake in form of an asynchronous motor driven via a frequency inverter with energy recovery.

The specimens are located in a slot between drive side and load side. They are mounted on a pallet which is adapted to the rig via defined interfaces, realized by aligning couplings. So preparation for new tests may be organized parallel to testing on the rig and exchange is realized in a safe manner and a short time (Fig. 3).

Next to the test rig is the pulley tower located (Fig. 4). In connection with a rope drum unit as specimen on the rig this completes to a full hoisting system. Maximum load is $m=1 t$, reevings $1 / 1,2 / 1$ and $4 / 1$ can be realized. The special design allows a quick change to part 
loads $\mathrm{m}=250 \mathrm{~kg}, \mathrm{~m}=500 \mathrm{~kg}$ and $\mathrm{m}=750 \mathrm{~kg}$ as well as between the different reevings. This hoisting system is the basis for testing of safety devices for hoists.

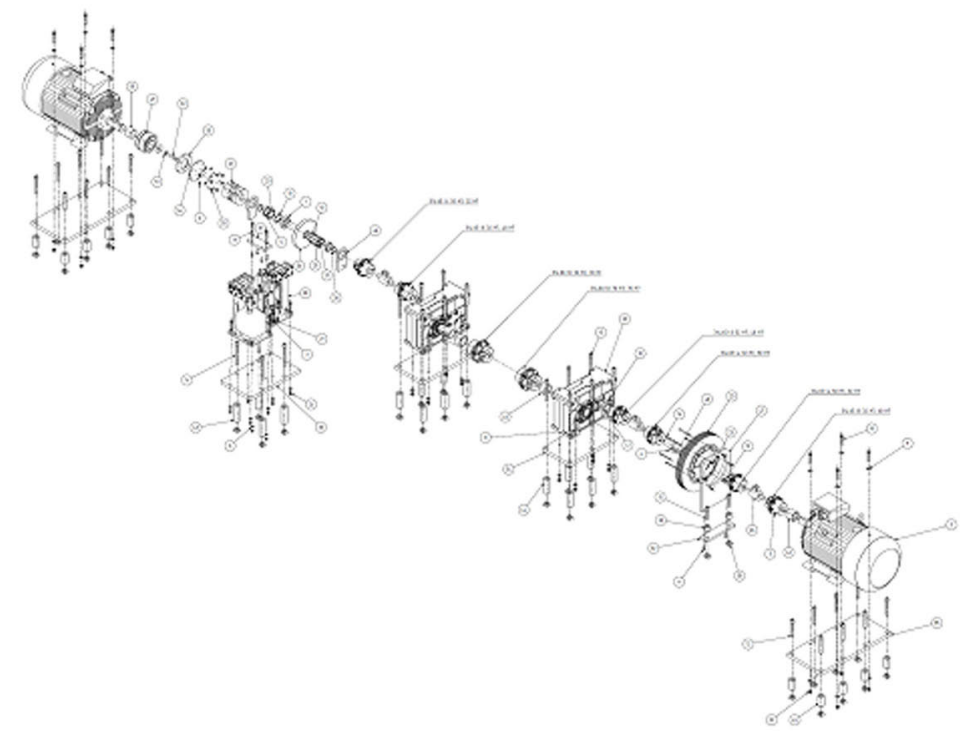

Fig. 3. Mechanical design of the drive side and the load side of testing rig
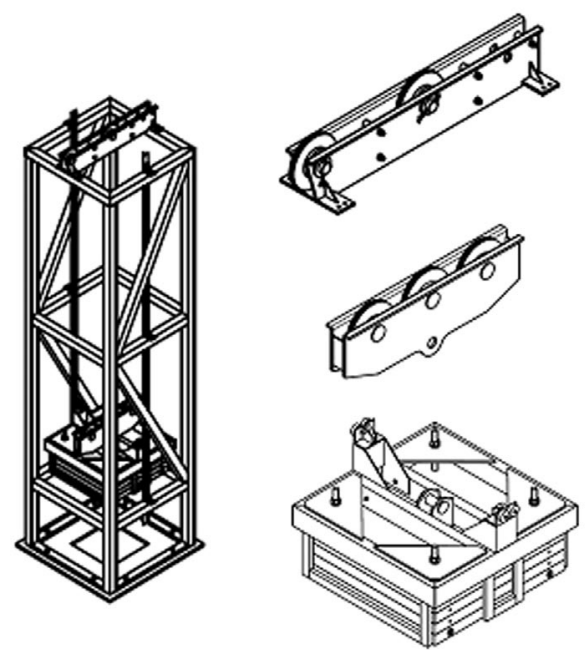

Fig. 4. Pulley tower (left) with top sheave (top), bottom sheave (middle) and load attachment device including load (bottom)

Elements of the multi-stage safety level are (Fig. 5):

Level 1 "Information": A corresponding information informs each person entering the hall about the presence of the testing device and main safety instructions.

Level 2 "Authorized persons": A list will be kept of the persons authorized to perform certain activities related to the test facility.

Level 3 "Walkway": All persons in the machine hall have to move exclusively on the marked walkway in the middle of the hall.

Level 4 "Ground marking": The yellow-black ground marking must not be passed. 
Level 5 "Protection wall": In order to avoid gripping into the test device and to shield from the testing device protective wall of $1.5 \mathrm{~m}$ height is installed on the front edge of the test bed.

Level 6 "Local protection equipment": If tests are carried out on the rig, which systematically include the destruction of components, the potential destruction areas are to be isolated by means of the planned local protection device.

Level 7 "Light grid": If continuous tests are performed unattended on the test stand, the test bench area is monitored on all sides by a light grid. The interruption of the light grid leads to the immediate stop of the test stand.

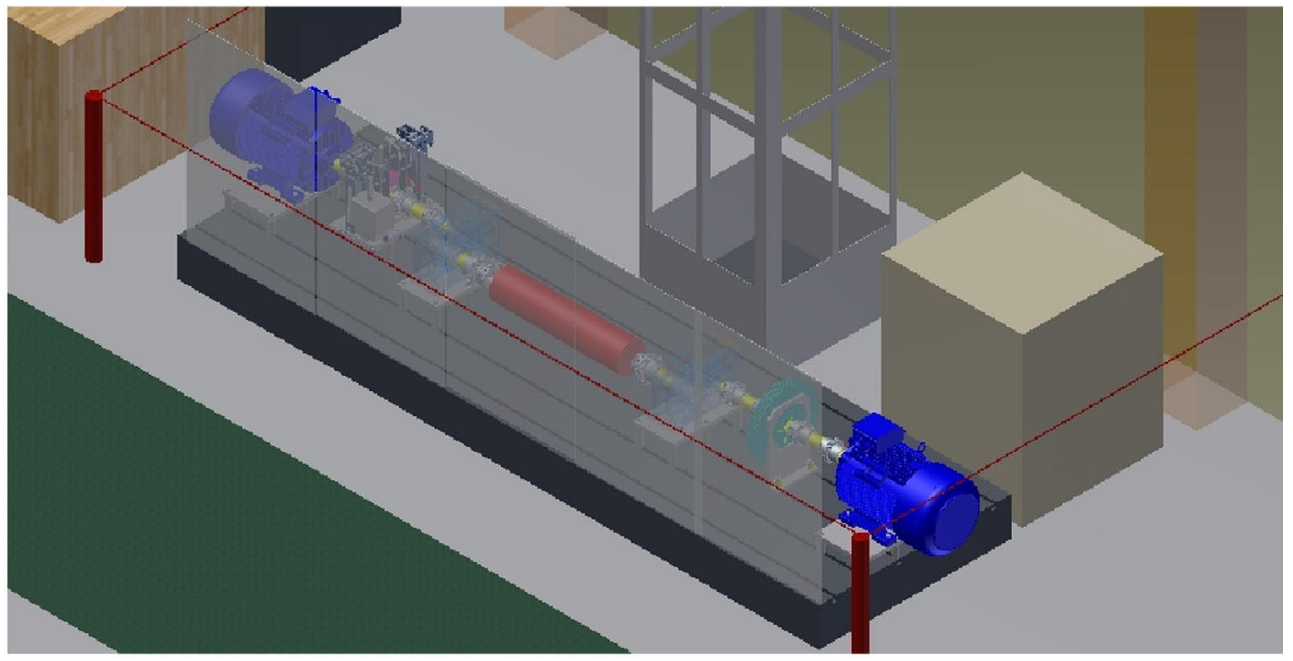

Fig. 5. Elements of the multi-stage safety level

\subsection{Measurement and Control}

The testing rig comprises three measuring shafts: The first one is located between brake and gearing on the drive side. Its main purpose is the measurement of motor actions, especially in the hoist modus. Two further measuring shafts are located on the load side, one between gearing and magnet powder brake and one between magnet powder brake and motor. Main task of these measuring devices is the collection of data related to the braking actions. All measuring shaft deliver a signal on the speed beside the torque signal as well.

The disc brakes are controlled in their position by switches. The brakes comprise, in addition to the motoric drive, hand levers for lifting. Switches control the position of these hand levers as well.

A load-measuring bolt is located at the fixation point of the rope at the top of the pulley tower.

Limit switches for the hoisting movement of the load are located in the upper and the lower position.

In case of continuous tests a light grid secures the test rig.

As testing programs change the alternation between different control systems takes place. Basically the different control systems consider the different nature of continuous testing and transient testing, both of which are executed on the rig. 


\section{Transport and assembly}

Transport of all components into the hall did not require special efforts. Trucks with the components could enter the hall via a gate with a large headroom. Unloading was done by a $10 \mathrm{t}$ bridge crane with a maximum hook height over floor of $\mathrm{H}=4.30 \mathrm{~m}$. With this unloading of the biggest part, the test bed with $\mathrm{m}=6670 \mathrm{~kg}$, was realised as well as other big components like the pulley tower structure.

As a first step of assembly, the test bed was adjusted. This sounds easier than it was done. The test bed is rather a flexible than a rigid body. Due to this, a certain strategy had to be applied to gain a plane and horizontal test bed surface. Afterwards further equipment was installed mechanically as supports, drive motor, safety clutch, alignment coupling, and motor side brakes (Fig. 6).

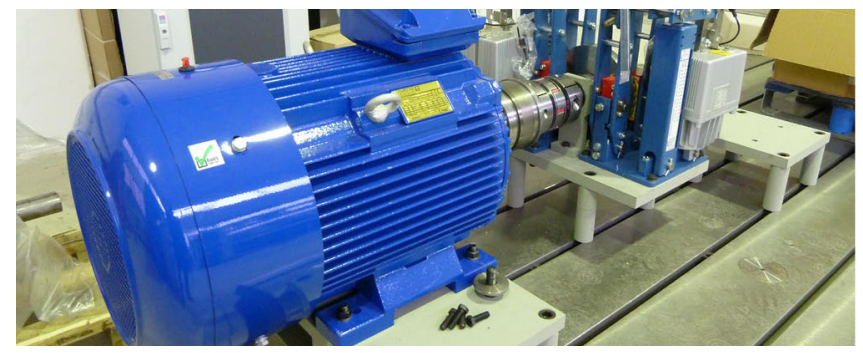

Fig. 6. Mechanical assembly of drive side

\section{Outlook}

Next steps to be carried out are: Mechanical installation of drive side, mechanical installation of load side, mechanical installation of pulley tower, installation of safety devices, electrical installation, definition of detailed requirements of control system, programming and installation of control system, commissioning via defined test scenarios.

\section{References}

1. S. Vöth, Proceedings of the 17th ITI-Symposium, ITI, 127 (Dresden, 2014)

2. S. Vöth, J. Sippel, Eigenschaften von drehmomentgesteuerten Schaltkupplungen nach dem Rastprinzip, Der Konstrukteur, Antreiben-Steuern-Bewegen, p. 50-52, Vereinigte Fachverlage, 2014

3. BG Holz und Metall (Hrsg.): Unfallverhütungsvorschrift, DGUV Vorschrift 52, Krane, 2013

4. Deutsche Gesetzliche Unfallversicherung (Hrsg.): BGI/GUV-I 5139, Information, herstellen und Betreiben von Geräten und Anlagen für Forschungszwecke, CEKonformität und Betriebssicherheit, 2011 